\title{
The neutrophilic and fibrinolytic response to talc can predict the outcome of pleurodesis
}

\author{
K. Psathakis*\#, E. Calderón-Osunađ, B. Romero-Romero", J. Martin-Juan`, \\ A. Romero-Falcón" and F. Rodriguez-Panadero"
}

ABSTRACT: It was hypothesised that monitoring neutrophil and D-dimer (DD) levels into the pleural fluid, after talc instillation, could predict the outcome of pleurodesis.

The current authors investigated a total of 168 patients with malignant pleural effusion, who were treated with talc poudrage. According to the outcome the patients were categorised into one of two groups, either successful or failed pleurodesis. In all cases, pleural fluid neutrophils and DDs were determined on serial measurements at $0,3,24$ and $48 \mathrm{~h}$ after the procedure. The time course of these parameters was assessed in both groups and the time point at which they could better predict the outcome was further explored.

Neutrophils rose rapidly after talc poudrage in both groups, reaching a plateau at $24 \mathrm{~h}$, although in successful pleurodesis this response was significantly higher. DD dropped markedly at $24 \mathrm{~h}$ in the group with the successful outcome, but it did not show significant changes in the other group. A cut-off value of $61 \%$ for neutrophils and $61 \mathrm{mg} \cdot \mathrm{L}^{-1}$ for the $\mathrm{DD}$ at $24 \mathrm{~h}$ yielded the best prognosis for successful pleurodesis.

The current authors conclude that serial measurements of neutrophil and D-dimer values into the pleural fluid after talc poudrage could be used as predictors of the outcome of pleurodesis.

KEYWORDS: D-dimer, fibrinolysis, inflammation, neutrophil, pleurodesis, talc

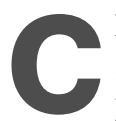
hemical pleurodesis intends to achieve a symphysis between visceral and parietal pleural layers, in order to prevent the accumulation of either fluid or air in the pleural space. The palliative treatment of malignant pleural effusions (MPEs) is one of the main indications for pleurodesis [1].

There is a long list of sclerosant agents that have been proposed for pleurodesis [2]. Presently, talc is considered as the preferable agent as it is effective, cheap, widely available and associated with minimal side-effects in most studies [3, 4].

The pathophysiological mechanisms involved in pleurodesis are still unclear. They may be specific to the agent used, but they may all follow a common final pathway. It has been hypothesised that after the instillation of the sclerosant agent an activation of the normal mesothelial cells follows, which in turn is followed by the activation of a coagulation cascade and the inhibition of fibrinolysis into the pleural space. The accumulation of fibrin into the pleural cavity serves as a fibrin bridge between the visceral and parietal pleura, which is the first step for fibroblast recruitment and the formation of fibrous tissue [1]. According to this hypothesis, it was found that increased levels of D-dimer (DD) in the pleural cavity after talc instillation, which reflected increased fibrinolytic activity, were associated with the failure to develop talc pleurodesis [5]. Previous observations also demonstrated that after talc instillation a neutrophilic inflammation was elicited into the pleural cavity [6]. Although the role of polymorphonucleates (PMN) in achieving pleurodesis is still unclear, it was found that the intensity of neutrophilic inflammation was higher in cases where pleurodesis was eventually successful, compared with the cases where pleurodesis attempts failed [5].

The current authors hypothesised that combined serial measurements of the PMN and DD values into the pleural space, after talc instillation, could be used to predict the outcome of pleurodesis.

The aim of this study was to monitor the intensity of the neutrophilic response (PMN levels) and the fibrinolytic activity (DD levels) into the pleural fluid, after talc insufflation, in patients with MPE. The current authors' main objective was to examine whether these parameters could be used as predictors for the outcome of pleurodesis. A secondary objective was to examine the relation between PMN and DD into the pleural cavity, during the response to talc, as well as the association of the pleurodesis outcome with the local disease extension.
AFFILIATIONS

*Dept of Pneumonology, Army General Hospital of Athens, Athens, Greece.

\#Respiratory Endoscopy Unit, and "Respiratory Endoscopy Unit, Unidad Médico-Quirúrgica de Enfermedades Respiratorias, Hospital Universitario Virgen del Rocío, Sevilla, Spain.

CORRESPONDENCE

K. Psathakis

Dept of Pneumonology

Army General Hospital of Athens

Liakataion 15

11474 Gyzi

Athens

Greece

Fax: 302107494095

E-mail: kpsazakis@hol.gr

Received:

August 202005

Accepted after revision:

December 032005

\section{SUPPORT STATEMENT}

This work was supported in part by a grant, RT 03/11 RED RESPIRA, from the Instituto de Salud Carlos III, Spain. 


\section{MATERIAL AND METHODS}

\section{Subjects}

The present authors prospectively studied 168 patients with a unilateral MPE. Patients' characteristics are shown in tables 1 and 2. All the patients were referred to the Hospital Universitario Virgen del Rocío (Seville, Spain) Endoscopy Unit for a diagnostic thoracoscopy and/or palliative treatment with talc pleurodesis. The diagnosis was established either by thoracoscopic pleural biopsy, performed at the time of the study or it was already known from a previous pleural fluid cytology. Patients who were proven to have benign pleural effusions were not included in the study. Patients who lived $<1$ month after the procedure were also excluded. None of the patients had previously been treated for pleural disease or had undergone invasive diagnostic procedures for pleural disease, other than thoracocentesis. All patients gave informed consent and the study was approved by the Hospital Universitario Virgen del Rocío Ethics Committee.

\section{Thoracoscopy and pleurodesis outcome}

Thoracoscopy was performed under local anaesthesia using an identical technique on all of the patients. Pleural lesions were rated during thoracoscopy, following a previously published method [7]. Talc poudrage for pleurodesis was performed during thoracoscopy and lung re-expansion was achieved as previously described [8]. The current authors used a mean (range) dose of 5.6 (4-6) g asbestos-free, sterile, dry talc powder (Steritalc; Novatech, Grasse, France). Thoracoscopy and talc poudrage were always performed a minimum of 1

\begin{tabular}{lc} 
TABLE 1 & Patients' characteristics \\
Patients & 168 \\
Group & 155 \\
$\quad$ Successful pleurodesis & 13 \\
$\quad$ Failed pleurodesis & \\
Sex & 81 \\
$\quad$ Male & 87 \\
Female & $62 \pm 14(91-16)$ \\
Age yrs & \\
\hline & \\
Data presented as $\mathrm{n}$ or mean \pm SD (range).
\end{tabular}

\begin{tabular}{lccc} 
TABLE 2 & Aetiology of malignant pleural effusions \\
\hline Primary tumours & Cases & \multicolumn{2}{c}{ Group } \\
\cline { 3 - 4 } & & $\begin{array}{c}\text { Successful } \\
\text { pleurodesis }\end{array}$ & $\begin{array}{c}\text { Failed } \\
\text { pleurodesis }\end{array}$ \\
\hline Lung & & 47 & 2 \\
Breast & $49(29)$ & 33 & 1 \\
Mesothelioma & $34(20)$ & 20 & 5 \\
Lymphoma & $25(15)$ & 11 & 2 \\
Other origin\# & $13(8)$ & 33 & 2 \\
Unknown origin & $35(21)$ & 11 & 1 \\
\hline
\end{tabular}

Data are presented as $\mathrm{n}$ or $\mathrm{n}(\%)$. *: Ovary, colon, stomach, others. month after the last chemotherapy. The next chemotherapy was given at least 3 weeks later. In patients with mesothelioma, local radiotherapy was applied at the site of entry 3 weeks after the thoracoscopy, to prevent neoplastic infiltration of the chest wall [9].

The outcome of pleurodesis in each case was evaluated 1 month after the procedure and at 3-month intervals thereafter until death, using previously published criteria [10]. According to the outcome, the patients were then categorised into two groups, either successful (S) or failed (F) pleurodesis. Total leukocyte and neutrophil blood cell counts were normal in both patient groups at baseline (before thoracoscopy).

\section{Pleural fluid sample collection and analysis}

Pleural fluid samples were collected by thoracocentes is immediately before the induction of pneumothorax for thoracoscopy and again at 3, 24 and $48 \mathrm{~h}$ after the procedure, through the chest tube. The pleural fluid samples were immediately stored in plastic containers with sodium citrate (ratio of 5:1, respectively) and were processed within $30 \mathrm{~min}$ after collection. After the centrifugation of the samples, the cells were collected and direct smears, as well as cytospin slides, were prepared. Cell staining was performed with Quick Panoptic stain (Química Clínica Aplicada, Amposta, Spain). Cell differentiation was conducted by counting 400 cells per slide and PMN levels were expressed as the percentage of the total nucleated cells.

In the supernatant of each sample DD levels were measured by the sandwich ELISA technique (NycoCard kit; Axis-Shield, Oslo, Norway) and expressed as $\mathrm{mg} \cdot \mathrm{L}^{-1}$. The method had a detection limit of $0.1 \mathrm{mg} \cdot \mathrm{L}^{-1}$.

\section{Statistical analysis}

Normal distribution of the various parameters was assessed by Shapiro-Wilks test. Homogeneity of variance was assessed by the Box's M-test. Patients' characteristics were expressed as mean \pm SD. PMN and DD values were given as means with 95\% confidence intervals (CIs). The time course of PMN and DD was assessed with repeated measures of ANOVA with one-within factor (time with four levels) and one-between factor, with two levels (S and F patients). Post-hoc Bonferroni-adjusted tests were performed to pinpoint differences. Receiver-operating characteristic curves were constructed in order to assess at which time-point the two parameters (PMN, DD) contained better prognostic information for an outcome. Pearson's correlation coefficient was used to assess the extent of association between continuous parameters (PMN and DD). Unpaired t-test for independent samples was used to assess whether the score of lesions between the two groups ( $\mathrm{S}$ and $\mathrm{F}$ ) was different. A p-value $<0.05$ was considered significant.

\section{RESULTS}

The outcome of talc poudrage could be assessed in 168 patients, as they had at least one follow-up, 1 month after the procedure. In 155 patients pleurodesis was successful and in 13 patients it was failed. The success rate of pleurodesis for talc poudrage, in the current study was $92 \%$. Mesotheliomas accounted for up to $38 \%$ of the failures, and most of those failures showed a poor neutrophilic response to talc. 
Repeated measures ANOVA showed that the mean PMN values in the $S$ group of patients rose rapidly $(p<0.001)$ during the first few hours, reaching a peak at $24 \mathrm{~h}$ (changing from 7 to $50 \%$ within $3 \mathrm{~h}$ and then to $79 \%$ at $24 \mathrm{~h}$ ) where it remained practically constant for the next day. The mean PMN values in the F group of patients rose during the first $3 \mathrm{~h}$ at the same rate as in the $\mathrm{S}$ group, but the increase rate during the remaining $21 \mathrm{~h}$ was significantly less $(\mathrm{p}=0.005)$ than those with a successful outcome. The mean PMN values in the F group of patients at $24 \mathrm{~h}$ were not significantly greater than those at $3 \mathrm{~h}$ $(p=0.73)$ or than those at $48 \mathrm{~h}(\mathrm{p}=0.85$, table 3 , fig. 1$)$.

The mean PMN values did not differ between the two groups of patients at 0 and $3 \mathrm{~h}$ after talc poudrage $(\mathrm{p}=0.30$ and 0.81 , respectively), but they were significantly higher in the $S$ group at 24 and $48 \mathrm{~h}(\mathrm{p}=0.023$ and 0.027 , respectively; fig. 1$)$.

The mean DD values in the $S$ group of patients started to drop significantly $3 \mathrm{~h}$ post-talc application, falling from 86 to $35 \mathrm{mg} \cdot \mathrm{L}^{-1}$ by the end of the day, where it remained for the

\begin{tabular}{|c|c|c|c|c|c|}
\hline \multirow[t]{3}{*}{ TABLE 3} & \multicolumn{5}{|c|}{$\begin{array}{l}\text { The mean values of serial polymorphonucleates } \\
\text { (PMN) and D-dimer (DD) measurements in } \\
\text { patients with successful (S) and failed (F) } \\
\text { pleurodesis }\end{array}$} \\
\hline & \multirow[t]{2}{*}{ Outcome } & \multicolumn{4}{|c|}{ Sample time $h$} \\
\hline & & 0 & 3 & 24 & 48 \\
\hline \multirow[t]{2}{*}{ PMN \% } & $\mathbf{s}$ & $7(5-10)$ & $50(44-57)$ & 79 (74-83) & 75 (70-79) \\
\hline & $\mathbf{F}$ & $13(6-20)$ & 48 (28-69) & 59 (44-73) & $56(42-70)$ \\
\hline \multirow[t]{2}{*}{$\mathrm{DD} \mathbf{m g} \cdot \mathrm{L}^{-1}$} & $\mathbf{s}$ & 87 (74-101) & 86 (73-99) & $35(27-44)$ & $34(25-44)$ \\
\hline & $\mathbf{F}$ & $86(37-135)$ & 137 (89-184) & $105(74-136)$ & $82(48-116)$ \\
\hline
\end{tabular}

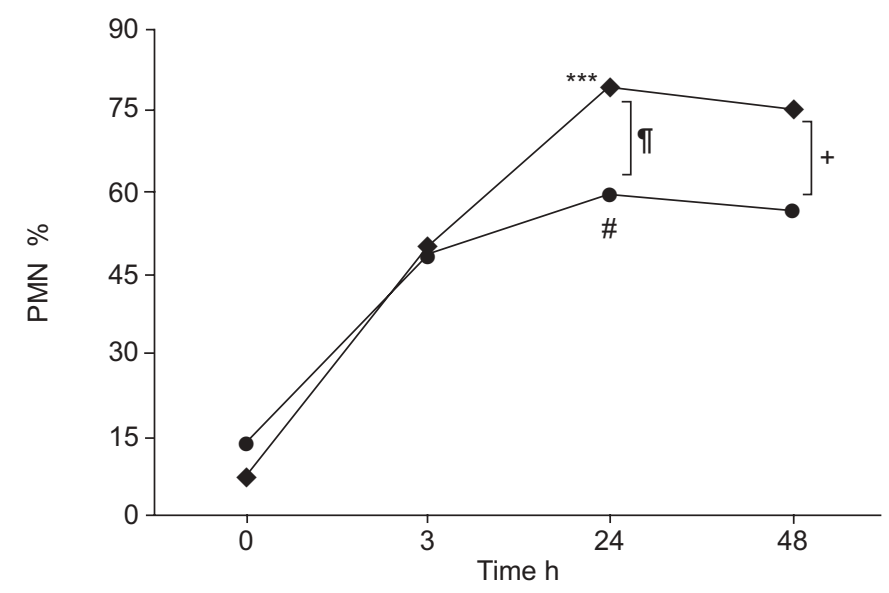

FIGURE 1. The time course of mean polymorphonucleates' (PMN) values in the two groups of patients. In the successful pleurodesis group $(\bullet)$ the PMN rose significantly and reached a plateau at $24 \mathrm{~h}\left({ }^{* *}: \mathrm{p}<0.001\right)$. The failed pleurodesis group ( $\bullet$ followed a similar, but significantly less intense, pattern of response $(\#: p=0.005)$. The difference of the mean PMN values between the two groups was not significant at 0 and $3 \mathrm{~h}$, but it was significant at 24 and $48 \mathrm{~h}$. ${ }^{* *}$ : $\mathrm{p}<0.001$; \#: $p=0.005 ;{ }^{*}: p=0.023 ;{ }^{+}: p=0.027$ next day $(p<0.001)$. The DD changes did not reach statistical significance $(p=0.30)$ during the $48-h$ period in the $F$ group. Unlike the $S$ group of patients though, DD increased during the first $3 \mathrm{~h}$ (table 3, fig. 2).

The mean DD values did not differ between the two groups at 0,3 or $48 \mathrm{~h}$ ( $\mathrm{p}=0.78,0.061$ and 0.67 , respectively), but they were significantly lower in the $\mathrm{S}$ group at $24 \mathrm{~h}$ after talc poudrage ( $\mathrm{p}=0.008$, fig. 2$)$.

PMN values at $24 \mathrm{~h}$ gave the best prognosis for successful pleurodesis. A cut-off value of $61 \%$ yielded $82 \%$ sensitivity and $75 \%$ specificity. DD at $24 \mathrm{~h}$ had a similar prognostic value. A cut-off DD value of $61 \mathrm{mg} \cdot \mathrm{L}^{-1}$ yielded 85 and $80 \%$ sensitivity and specificity, respectively.

In this group of patients, a cut-off value of $61 \%$ for the PMN at $24 \mathrm{~h}$ was calculated to have a positive predicted value (PPV) of $95 \%$ and a negative predictive value (NPV) of $21.4 \%$ for successful pleurodesis. A cut-off value of $61 \mathrm{mg} \cdot \mathrm{L}^{-1}$ for the DD at $24 \mathrm{~h}$ was calculated to have a PPV of $97.4 \%$ and a NPV of $12.2 \%$ for successful pleurodesis.

PMN and DD were marginally correlated before pleurodesis $(\mathrm{r}=0.193, \mathrm{p}=0.046)$. After the procedure, PMN showed a significant negative correlation with DD at $24 \mathrm{~h}(\mathrm{r}=-0.3$, $\mathrm{p}=0.004)$ and at $48 \mathrm{~h}(\mathrm{r}=-0.282, \mathrm{p}=0.014$, table 4$)$.

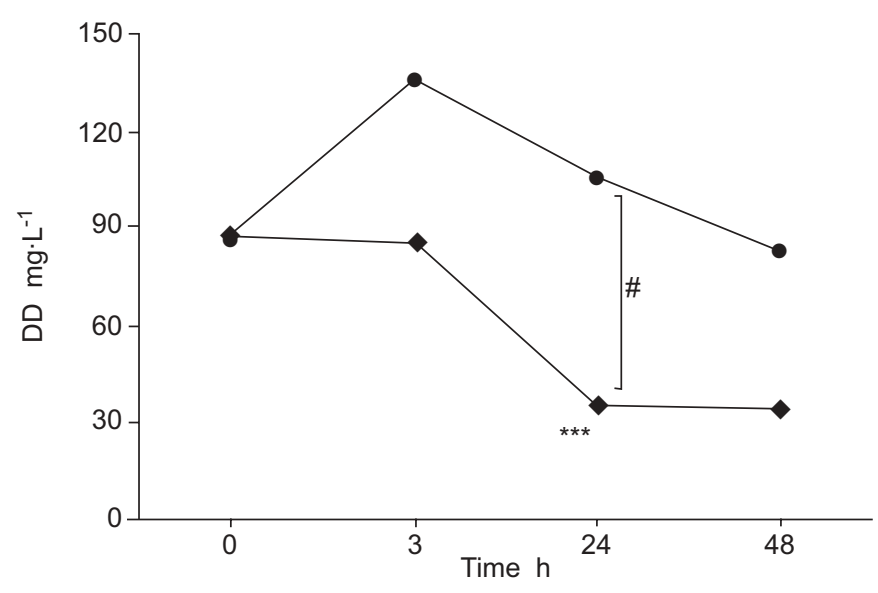

FIGURE 2. The time course of mean D-dimer (DD) values in the two groups of patients. In the successful pleurodesis group $(\bullet)$ there was a marked drop of DD at $24 \mathrm{~h}$ (***: $\mathrm{p}<0.001$ ). In the failed pleurodesis group $(\bullet)$ DD values remained practically unchanged. The difference of the mean $\mathrm{DD}$ values between the two groups was significant at $24 \mathrm{~h}\left({ }^{*}: \mathrm{p}=0.008\right)$.

\begin{tabular}{lcccc} 
TABLE 4 & $\begin{array}{l}\text { Correlations between serial } \\
\text { polymorphonucleates and D-dimer values }\end{array}$ \\
& \multicolumn{4}{c}{ Sample time $\mathbf{~ h}$} \\
\cline { 2 - 4 } & $\mathbf{0}^{\#}$ & $\mathbf{3}$ & $\mathbf{2 4}^{+}$ & $\mathbf{4 8}^{+}$ \\
\hline $\mathbf{p}$-value & 0.046 & 0.884 & 0.004 & 0.014 \\
$\mathbf{r}$ & 0.193 & -0.015 & -0.3 & -0.282 \\
\hline & r: Regression coefficient. ${ }^{*}$ : Marginal correlation; ${ }^{+}$: strong correlation.
\end{tabular}


The mean score of pleural lesions was slightly less in the $S$ group of patients $(5.36 \pm 1.7)$ than in the F group $(6.2 \pm 1.3)$, but the difference was not significant $(p=0.29)$.

\section{DISCUSSION}

In the present study, the current authors monitored the inflammatory response and the changes of fibrinolytic activity into the pleural cavity, for two consecutive days, after talc insufflation. The current authors measured the serial PMN and DD values of the pleural fluid, as indices of the response to talc poudrage, and the authors' most interesting finding was that the profile of this response could predict the outcome of pleurodesis.

PMN levels, in the first $24 \mathrm{~h}$ after talc poudrage, were significantly increased when compared with the baseline values and after this time they reached a plateau. This profile was similar in both groups of patients (S and F), although after the first $3 \mathrm{~h}$ PMN reached significantly higher levels in the $S$ than in the $F$ group. This difference remained significant, at least, for the next $45 \mathrm{~h}$ after talc poudrage. These findings may imply that the more intense the neutrophilic response to talc, the more likely the pleurodesis is to be successful. The highest failure rate was found in mesotheliomas in the current series, and most of those cases showed a poor neutrophilic response to talc. The current authors thus speculate that the tumoural mesothelium was unable to react adequately to talc stimulation. Also, the DD profile in most of those failed cases showed an increased fibrinolytic activity, which is in relation with the well known pro-fibrinolytic expression of many tumours in advanced stages [11, 12].

DD values, in the $S$ group, showed a marked drop in the first $24 \mathrm{~h}$ after talc poudrage and remained there for the next $24 \mathrm{~h}$. In the F group the DD values remained practically unchanged, since they oscillated around the baseline levels without significant changes.

In successful pleurodesis, PMN and DD values showed their most dramatic changes during the first $24 \mathrm{~h}$. At this time, a dissociation between the PMN and DD curves was observed (fig. 3), with the PMN reaching their highest levels and DDs reaching their lowest levels. Both values remained in a plateau for the next $24 \mathrm{~h}$. It seems that the events taking place in the first $24-48 \mathrm{~h}$, in the pleural cavity, may be critical for the outcome of pleurodesis. In order to achieve a successful pleurodesis, it is crucial for the lung to have been re-expanded at this period of time and the two pleural layers to have been opposed [1]. This apposition facilitates a primary, loose connection of the two layers by a locally elaborated transitional fibrin neomatrix. Remodelling of the fibrin neomatrix by migration of inflammatory cells and fibroblast into the pleural cavity will eventually result in the formation of fibrotic tissue [13]. It is evident that the early apposition of the parietal and visceral pleura and the formation of the fibrin neomatrix are both necessary for the achievement of pleurodesis [1, 8].

Previous reports underlined the role of the coagulation and the fibrinolytic pathways in influencing inflammatory and fibroproliferative reactions into the pleural space [14]. Pleural injury and repair is characterised by disordered fibrin turnover, the accumulation and organisation of fibrinous exudates, which has been correlated with the development of pleural fibrosis

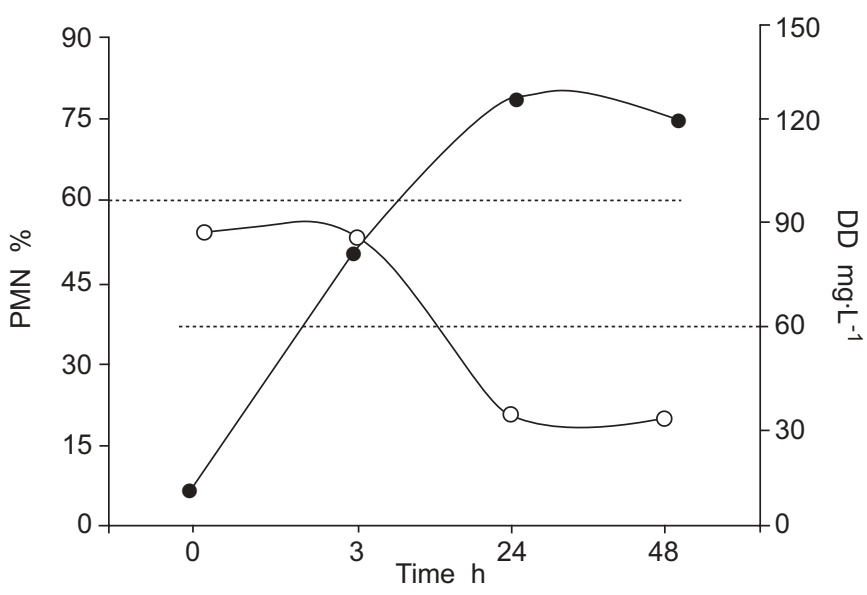

FIGURE 3. The characteristic dissociation of the curves, representing the time course of polymorphonucleate (PMN: - ) and D-dimer (DDs: O) mean values, in the successful pleurodesis group of patients. - - -: The cut-off values for PMN and $\mathrm{DD}$, respectively, that gave the best prognosis for the outcome of pleurodesis.

[15]. Intrapleural coagulation is initiated by increased local expression of tissue factor and concurrent downregulation of fibrinolysis owing mainly to increased expression of plasminogen activator inhibitor-1. In the current study the decreased levels of $\mathrm{DD}$, that were found in patients with successful pleurodesis, probably reflected these events. As a result of these changes, formation of adhesions between the visceral and parietal pleural surfaces occurs. As this process evolves, the fibrin strands become firmly anchored at the pleural surface by fibroblast and progressively exhibit more collagen, following the traditional progression of events associated with wound healing $[16,17]$.

The role of PMN in pleurodesis is unclear but it has been shown that proteolytic enzymes, released by PMN may cause mesothelial denudation, which has a key role for the development of pleural fibrosis [18, 19]. Proteolytic enzymes may also degrade many coagulation proteins, thus modulating both the thrombotic and the fibrinolytic systems [20]. PMN interact mostly with platelets to activate coagulation [21], but also enhance fibrin deposition through platelet-independent mechanisms [22]. It has been shown that the migration of PMN into the pleural space facilitates the exudation of fibrinogen [23].

In the present study, it was observed that PMN and DD values were marginally correlated before talc poudrage, but they showed a strong negative correlation within 24 and $48 \mathrm{~h}$. Although the nature of this interrelation is obscure, it seems that a successful pleurodesis with talc needs an intense neutrophilic reaction with concurrent suppression of fibrinolysis. This loss of fibrinolytic activity might be caused by PMNmediated degradation of plasmin, as well as both urokinase and tissue-type plasminogen activators [24].

The current authors found that PMN values $>61 \%$, and DD values $<61 \mathrm{mg} \cdot \mathrm{mL}^{-1}, 24 \mathrm{~h}$ after talc poudrage, could best predict a successful result. However, these cut-off points should be considered as indicative because the efficacy of talc as a sclerosant (success rate $=92 \%$ ) might produce a bias, due to 
the small number of patients in the F group. The results from the current study imply that cases that tend to have a different pattern of response to talc than that summarised in figure 3 will probably fail. In such cases additional measures could be considered to enhance local reactions, such as the application of an additional dose of talc through the thoracic tube (slurry) or the prolongation of pleural drainage for a few days with increased suction.

The present authors conclude that talc, shortly after its instillation, induces a neutrophilic reaction and causes a decrease of the fibrinolytic activity into the pleural cavity. The intensity of these reactions, reflected by the levels of polymorphonucleate and D-dimer in pleural fluid after talc poudrage, seems to correlate with the outcome of pleurodesis. Since the measurement of both polymorphonucleate and Ddimer values can be performed by simple and easily available techniques, the current authors believe that these parameters can be useful in monitoring the ongoing pleurodesis process after the application of talc.

\section{REFERENCES}

1 Rodriguez-Panadero F, Antony VA. Pleurodesis: state of the art. Eur Respir J 1997; 10: 1648-1654.

2 Walker-Renard PB, Vaughan LM, Sahn SA. Chemical pleurodesis for malignant pleural effusions. Ann Intern Med 1994; 120: 56-64.

3 Light RW. Talc for pleurodesis? Chest 2002; 122: 1506-1508.

4 Rodriguez-Panadero F. Current trends in pleurodesis. Curr Opin Pulm Med 1997; 3: 319-325.

5 Rodriguez-Panadero F, Segado A, Martin-Juan J, Ayerbe R, Torres-Garcia I, Castillo J. Failure of talc pleurodesis is associated with increased pleural fibrinolysis. Am J Respir Crit Care Med 1995; 151: 785-790.

6 van den Heuvel MM, Smit HJM, Barbierato SB, Havenith CEG, Beelen RHJ, Postmus PE. Talc-induced inflammation in the pleural cavity. Eur Respir J 1998; 12: 1419-1423.

7 Sanchez-Armengol A, Rodriguez-Panadero F. Survival and talc pleurodesis in metastatic pleural carcinoma, revisited. Report of 125 cases. Chest 1993; 104: 1482-1485.

8 Rodriguez-Panadero F, Antony VA. Therapeutic local procedures: pleurodesis. Eur Respir Monograph 2002; 7: 311-326.

9 Boutin C, Viallat JR, Aelony Y. Practical Thoracoscopy. Berlin, Germany, Springer Verlag, 1991.

10 Antony VA, Loddenkemper R, Astoul P, et al. ERS/ATS statement: management of malignant pleural effusions. Eur Respir J 2001; 18: 402-419.
11 Kockar C, Kockar O, Ozturk M, Dagli M, Bavbek N, Kosar A. Global fibrinolytic capacity increased exponentially in metastatic colorectal cancer. Clin Appl Thromb Hemost 2005; 11: 227-230.

12 Romero B, Gomez-Izquierdo L, Diaz-Cañaveral L, et al. Intrapleural fibrinolysis modulation in malignant pleural effusions. Eur Resp J 2001; 18: Suppl. 33, 517s.

13 Idell S. Pleural fibrosis. In: Light RW, Lee YCG, eds. Textbook of Pleural Diseases. New York, NY, USA, Arnold Publishers, 2003; pp. 96-108.

14 Idell S, Girard W, Koenig KB, McLarty J, Fair DS. Abnormalities of pathways of fibrin turnover in the human pleural space. Am Rev Respir Dis 1991; 144: 187-194.

15 Strange C, Tomlinson JR, Wilson C, Harley R, Miller KS, Sahn SA. The histology of experimental pleural injury with tetracycline, empyema and carrageenan. Exp Mol Pathol 1989; 51: 205-219.

16 Dvorak HF. Tumors: wounds that do not heal. Similarities between tumor stroma generation and wound healing. N Engl J Med 1986; 315: 1650-1659.

17 Sahn SA. Pleural fibrosis. An interaction of mesothelial cell injury, cytokines, and disordered fibrin turnover. J Bronchol 2004; 11: 3-5.

18 Davila RM, Crouch EC. Role of mesothelial and submesothelial stromal cells in matrix remodelling following pleural injury. Am J Pathol 1993; 142: 547-555.

19 Venaille TJ, Mendis AHW, Phillips MJ, Thompson PJ. Role of neutrophils in mediating human epithelial cell detachment from native basement membrane. J Allergy Clin Immunol 1995; 95: 597-606.

20 Imamura $T$, Kaneda $H$, Nakamura S. New functions of neutrophils in the arthus reaction: expression of tissue factor, the clotting initiator, and fibrinolysis by elastase. Lab Invest 2002; 82: 1287-1295.

21 Barnard MR, Linden MD, Frelinger AL 3rd, et al. Effects of platelet binding on whole blood flow cytometry assays of monocyte and neutrophil procoagulant activity. J Thromb Haemost 2005; 3: 2563-2570.

22 Goel MS, Diamond SL. Neutrophil enhancement of fibrin deposition under flow through platelet-dependent and -independent mechanisms. Arterioscler Thromb Vasc Biol 2001; 21: 2093-2098.

23 Saito M, Shima C, Takagi M, Ogino M, Katori M, Majima M. Enhanced exudation of fibrinogen into the perivascular space in acute inflammation triggered by neutrophil migration. Inflamm Res 2002; 51: 324-331.

24 Moir E, Robbie LA, Bennet B, Booth NA. Polymorphonuclear leucocytes have two opposing roles in fibrinolysis. Thromb Haemost 2002; 87: 1006-1010. 